\title{
Perspective
}

\author{
An occasional series in which contributors reflect on their careers and interests in psychiatry
}

\section{ThOMAS FreEMAN}

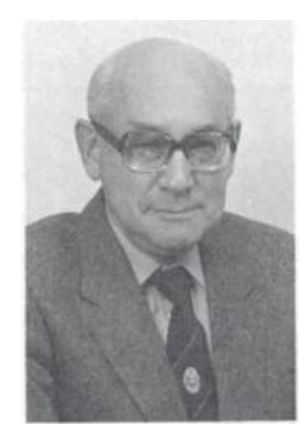

I qualified in Belfast (Queen's University) in 1942. I did not have any interest in psychiatry, having the ambition to become a clinical physiologist. I had worked with Henry Barcroft, who was professor of physiology. I joined the Army and later the Airborne Forces. Fortunately, the casualties expected amongst the medical personnel of the 6th Airborne Division during the Normandy incursion did not occur, leaving myself and other medical colleagues, who had just completed our parachute training, redundant. I was posted to France and in the late summer of 1944 found myself regimental medical officer to the 1st Battalion The Herefordshire Regiment. I must confess that it never occurred to me during the winter and spring of 1944-1945 that the emotional reactions and the physical expressions of anxiety encountered, particularly amongst the young conscripts, had anything to do with the subject of psychiatry.

In April, 1945 I was recalled from Germany and posted to the HQ Ist British Airborne Corps as general duty medical officer. There I met Bob Blair, who was the corps psychiatrist. Later he became consultant psychiatrist at Ivybridge Hospital in Devon. Listening to him made me appreciate that psychiatry embraced something more than the custodial care of the mentally deranged. The corps was preparing to be sent to India for the invasion of Malaya. A junior psychiatrist was required, but no-one was currently available who had both active service and parachuting experience. Bob Blair suggested to the senior medical officer (the Deputy Director of Medical Services, RAMC) that as a stop gap I could be sent for a three month crash course in psychiatry and then follow the HQ to India. I was glad to get the opportunity to learn something new and off I went to Northfields Military Hospital in June 1945.

Northfields comprised two clinical divisions. Tom Main, latterly Director of the Cassel Hospital, was in charge of one and Isaac Sutton, later superintendent of Friern Hospital, was in charge of the other. I was allocated to Sutton's division, where I was given a number of soldier patients. The majority of men in the hospital had recently been freed from prisonerof-war camps. I had no idea that Northfields, through the work of Bion and Rickman, had already established itself as a pioneering centre for group psychotherapy and what would come to be known as social psychiatry. S. H. Foulkes was currently working in Main's division and they were both actively engaged in furthering these developments. I had no involvement with this but I heard a great deal about it and about psychoanalysis.

I began to find the work interesting, possibly because I was now observing the long-term effects of the acute traumata I had witnessed at first hand during 1944-1945. I was told to encourage the patients to talk about their complaints, their experiences and their problems. I found this very difficult because they were anything but forthcoming. Perhaps I was fortunate being spared the distraction, or should I say the temptation, of embarking on drug treatment. In those days this was limited to the barbiturates and they had proved disappointing. An exception was their use in abreactive therapy. This introduced me to Freud and Breuer's traumatic theory of hysteria and their cathartic therapy.

I soon realised that if I were to become a psychiatrist I had to acquire a technique, an attitude of mind, which would enable me to help patients overcome the obvious difficulty they had in revealing their thoughts, feelings and memories. Psycho-analytic training seemed to be the answer. I had heard that a personal analysis was a requirement but otherwise I was quite ignorant of how long it would take, what else was involved and how it was to be obtained. Fortunately I met Martin James, for many years a prominent London psycho-analyst, and he said he would arrange an appointment with Anna Freud. I should add here that with the Japanese war ending in August 1945 I remained at Northfields until February 1946, when I was posted to the military wing of Clifton Hospital in York to learn something about mental hospital psychiatry. My stay there was brief but I benefited from some personal instruction from J. Iveson Russell, the superintendent. It was his firm opinion that in general the prognosis for psychotic 
attacks was much more favourable than that for neurotic disorders. Today I think I have an idea of what he meant by that.

When the time came for my meeting with Anna Freud in June $1946 \mathrm{I}$ had already been recalled to the Airborne Forces. The psychiatrist involved in the selection of volunteers for the Parachute Regiment and supporting arms, David Glendenning, had been demobilised. In the absence of anyone else and despite my slender experience of psychiatry and ignorance of selection procedures, I was instructed to get on with it. When I met Anna Freud she explained the situation currently existing in the London Institute with regard to training. If I applied and was accepted I could train with her group, with that of Melanie Klein or with the 'middle group'. I had made up my mind before I even saw her. I wanted to learn about Freud's method; later I might look into the new developments. I applied for the training, was accepted and arranged to begin my analysis as soon as I was released from the Army.

On demobilisation I began my six months exservice registrar post at St Ebba's Hospital, Epsom and started my analysis with Dorothy Burlingham, the friend and colleague of Anna Freud. This was a difficult time. In order to leave hospital each day at $4.0 \mathrm{pm}$ to go for the analysis, I had to agree to act as duty medical officer each weekend. My wife's stoicism was a great support at this time. At the end of the six month period the Postgraduate Medical Federation did not extend my registrarship. I applied for two posts. Meanwhile I had a telephone call from Louis Minski, superintendent of Belmont Hospital, formerly Sutton EMS hospital. He offered me a locum for six months: I refused this only to discover a few days later that I had been unsuccessful in both applications. I decided to telephone Minski. I asked him if the locum was still available. Characteristically he said "Come along, and see me". I was appointed locum and some months later he offered me a permanent registrarship. The sense of gratitude I experienced then has never left me.

Every viewpoint and every treatment in psychiatry was represented at Belmont. Insulin coma therapy, modified insulin treatment, ECT and ether abreaction were the province of William Sargant and Joe Shorvon. Group therapy, psychodrama, milieu therapy were the therapeutic levers of Maxwell Jones's Industrial Neurosis Unit. Psychoanalysis was represented by five staff members who were candidates at the London Institute. In spite of management difficulties arising from these different treatment methods, and the sharp divergences of view frequently expressed at the weekly clinical meetings, harmony prevailed. My first task at Belmont was to run the insulin coma unit and I did this for eighteen months. Patients were referred by senior colleagues. I never felt that I was compromising my psychoanaly- tic 'identity' by administering either insulin coma or electro shock therapy. I believe I was too interested in identifying the patients psychical reactions to their treatments. Indeed it was Dorothy Burlingham who encouraged me in this. The detailed notes I made then led to my first publication in the British Journal of Medical Psychology.

At Belmont there was no difficulty getting away for my analysis and when the time came for me to begin my first supervised case Louis Minski agreed to my finding a local patient and seeing her in hospital time. Every week I went with him to his psychiatric outpatient clinic at Sutton and Cheam General Hospital. This was a busy clinic. He would see four new patients and I would see the return visits. I learned from him how to cut through irrelevancies and get to the heart of the problem. I know I assimilated at least some of his common sense and pragmatic approach.

The Health Service had started and I was graded as a senior registrar. My analytic training was demanding more time and so Belmost became impracticable being so far from London. Although reluctant to leave I was fortunate to obtain a senior registrar post at the Tavistock Clinic which I held for 18 months. There I was introduced to group analytic work by Jock Sutherland and Geoffrey Thompson. I now had time for my second supervised case, for other psychotherapeutic work and for reading. However, I missed the wider fields of psychiatry. Shortly after qualifying as an Associate Member of the British Psycho-analytical Society Jock Sutherland told me that Ferguson Rodger, not long appointed as first professor of psychological medicine in Glasgow, was looking for an analytically trained psychiatrist to join his department which was then located at Glasgow Royal Mental Hospital (Gartnavel). I was instantly taken by this suggestion as I had always had the wish to leave London, preferably for Northern Ireland, but Scotland was attractive, not least because I am a Glaswegian by birth. For a brief period I was undecided about leaving London but unexpected events caused me to decide for Glasgow.

In Glasgow in 1952 there was considerable interest in psychoanalysis. This interest was due to Ferguson Rodger and also to Angus McNiven who was the superintendent of the Royal Mental Hospital. I obtained a part-time post which enabled me to begin independent psycho-analytic practice. At first some of my time was spent supervising the psychotherapeutic work of Ferguson Rodger's junior staff. Most of that group proceeded to London to train at the Psycho-analytic Institute. The remainder of my time was spent attempting to treat a number of the mental hospital patients. At the weekly clinical meetings and the discussions that frequently followed, it appeared to me that less emphasis was placed on the primacy of organic or psychological factors than in the South. Adverse life experiences were related to immediate 
causes of illness and similarly with elements of the predisposition. I was witnessing Meyerian psychiatry in action. McNiven, Ferguson Rodger and earlier D. K. Henderson, then professor in Edinburgh, had been pupils of Adolf Meyer at the Phipps Clinic in Baltimore. In 1927 D. K. Henderson had written his Textbook of Psychiatry with R. D. Gillespie at Gartnavel under the influence of Meyer's psychobiological theory of mental illness. The idea that psychical events generated by disturbing life experiences could be the immediate cause of psychotic illness and contribute to predisposition appealed to me. It is of interest that today Meyer's work is almost forgotten in the UK; even by those who over the past decade or so have been studying the role of external events in the precipitation and course of psychotic disorders.

In those days every mental hospital had its quota of middle-aged patients, often women, who suffered from severe chronic depressive states - at the time designated involutional melancholias. These patients had usually received many courses of ECT without beneficial effect. Influenced by my period at the Tavistock Clinic, I wondered if any of these patients would respond to long-term group psychotherapy. I was joined in this endeavour, which continued over the next two and a half years, by J. L. Cameron (Iain Cameron) who had arrived at Gartnavel at about the same time as myself. The group met thrice weekly and we met weekly with the nurses from the patients' wards. As this project prospered, the next year, 1953, Ferguson Rodger suggested that we might take a similar approach with schizophrenic patients who had been in the hospital for several years. It was a time when a number of British psychiatrists such as Bickford, T. P. Rees, Martin and others were initiating rehabilitation programmes for the chronic institutionalised patient. Our project was funded by the Henderson Research Scholarship in Mental Diseases. Iain Cameron was appointed as research psychiatrist and Andrew McGhie as research psychologist. This work involved nurses as well as patients and was therefore meant to be also a contribution to mental nursing education. The work in which Ferguson Rodger initially joined continued for three years. The results were published in 1958 in a monograph entitled Chronic Schizophrenia. I suppose we merely discovered for ourselves what Bleuler had described in 1911 - that changes in the symptoms and behaviour of established cases of schizophrenia are entirely determined by psychical reactions to external events.

I was now spending nearly all my NHS time in Gartnavel. Chlorpromazine had arrived in late 1953. At first the dosage was 75 mgms cautiously prescribed per day, but it was not long before enthusiastic colleagues were administering $1000 \mathrm{mgms}$ per day. This upset Angus McNiven, who could never be persuaded that chlorpromazine and its successors were anything other than dangerous symptomatic remedies to be handled with care. The 'furor sanandi' which repeatedly follows the introduction of a new anti-psychotic medication (e.g. haloperidol) reminds me of my insulin coma days. If 20 comas did not effect a remission, then $\mathbf{4 0}$ comas were required and sometimes what was called 'ECT in sopor'. I believe that when a psychotic patient is given time by a doctor or nurse, preferably by both, he will respond to chemotherapy in modest does. As for ECT, its indiscriminate use over more than 30 years nearly led to a ban on its use. Such a fate has virtually overtaken useful medications - the barbiturates and the minor tranquillisers. I fear the same may happen to the antidepressants.

In late 1957 I was thrust into a conflict as to the future direction of my career. David Yellowlees, director of the Lansdowne Clinic was due to retire. This clinic was located in the West End of Glasgow but administered by the Board of Management of Gartnavel. It had been founded in the early 1930s by David Yellowlees as a clinic for out-patient psychotherapy. It seemed logical that I as a trained psychotherapist, albeit of the Freud persuasion, should apply for the post and continue the development of the clinic. I felt it was something I ought to do but feared returning to a limited and narrow sphere of psychiatry. However I applied and was appointed. I remained part-time in order to continue my analytic practice. However after one year I so missed the mental hospital work that I became whole-time so that I could spend each morning at Gartnavel. I transformed my two remaining analytic patients into NHS patients and continued their treatment at the Lansdowne.

I like to think the clinic prospered under my directorship, which lasted for seven years. Two trained psychoanalysts, both Scottish medical graduates, joined the staff $-J$. M. Davie now of Toronto and Enid Caldwell now of Boston. Group and individual psychotherapy were the mainstays of the therapeutic programme. Trainee psychiatrists from all the psychiatric institutions in the Glasgow area attended for tuition in analytic psychotherapy, individual and group. We had general practitioner groups and monthly meetings when we had guest speakers from England, Scotland and Northern Ireland. I was periodically distracted by opportunities to take up posts in London, Baltimore and Topeka, Kansas, but I had an ambition, one that had precipitated me into the directorship of the clinic, to establish a psychoanalytic group in Glasgow; none existed nor does now outside London. I had discussions with senior analysts at the London Institute but it all came to naught, partly I believe, because of the London-centred bias of these colleagues. This disappointment may have played a part in my increasing 
disenchantment with the work of the clinicparticularly the group psychotherapy which I felt failed to reach the nucleus of the disorders, although there was often considerable therapeutic benefit. I became increasingly aware of the desire to spend more time in hospital practice and devote the rest to regular five times per week psychoanalytic treatment. I was perhaps going to swim against the tide as by 1963-1964 there was already talk of the mental hospital becoming superfluous. Hope was now pinned on the new medications and on the psychiatric unit of the general hospital. I strenuously opposed this, pointing to the fact that as yet we were without aetiologically based treatments. Chronically ill patients would remain with us; where else were they to go? Today we have the legacy of these optimistic forecasts and the actions which were based on them.

Changing circumstances in Glasgow enabled me to leave the Lansdowne Clinic in 1965, the year in which my colleagues Cameron and McGhie and I published a sequel to our Chronic Schizophrenia"Son of Chronic Schizophrenia" as McGhie humourously called it. With the agreement of my wife we went to Dundee, where Ivor Batchelor was the professor of psychiatry. I had a full-time post as a general psychiatrist. There I had ample opportunity to pursue my descriptive and psychoanalytical studies on functional psychoses and organic mental states, edit the British Journal of Medical Psychology in a more leisurely manner and also teach something of psychoanalytic psychiatry. On a periodic visit to the Hampstead Child Therapy Clinic in London (now the Anna Freud Centre) in 1966 Anna Freud asked me if I would be interested in using her newly developed profile schema with a psychotic patient. This was the beginning of my long association with the clinic. A group was formed which met monthly and consisted of Anna Freud, Dorothy Burlingham, Humberto Nagera who went to the USA in 1971, Clifford Yorke and Stanley Wiseberg. The aim was to study all varieties of mental illness from the psycho-analytic standpoint. After Dorothy Burlingham and Anna Freud died Yorke, Wiseberg and I continued with the work and do so to this day. In the not too distant future the fruits of our labours will make their appearance in print.

Throughout the years I never lost the wish to return to Northern Ireland. In 1968 unforeseen events heightened this wish and led me to apply for a post at
Holywell Hospital, Antrim. Holywell provided the psychiatric services for County Antrim, the population being about 350,000 . When I arrived there were four consultants, including myself. Until my retirement in 1984 I was engaged in every sphere of the hospital work, ran an out-patient clinic at the Lagan Valley hospital and and made many domiciliary visits. As I had opted for a maximum part-time post I was able to continue psycho-analytic practice, make my monthly trips to the Anna Freud Centre, continued writing and contributed to the University department of psychiatry's post-graduate programme. My years at Holywell were happy ones despite the great, and if I may so, excessive demands which were made in the early years on my colleagues Edna Casement, Artie Kerr and myself.

Looking back over more than $\mathbf{4 0}$ years in British psychiatry, much has changed and nothing has changed, as one might perhaps expect. There has been little movement in fundamental attitudes. The majority of academic establishments continue to adhere to the slogan 'Mental diseases are brain diseases', although the heuristic value of this has proved disappointing. There is the same scepticism about the value of psychoanalysis as a clinical discipline. Interest in the chronically ill psychotic patient is no greater than 50 years ago. Today these individuals are in danger of being subject to greater neglect outside mental hospitals, now that it has become possible to mask the more 'outrageous' manifestations of the illnesses with long-acting medications. The public are still suspicious of psychiatrists and psychiatry. Mental illness, psychotic or non-psychotics remains a stigma, despite protestations to the contrary by those who wish it were otherwise. What has changed? The atmosphere of mental hospitals had changed for the better and the patient population is quite different from what it was in the past. Psychiatry has become fragmented into community psychiatry, liaison psychiatry, psychogeriatrics, forensic psychiatry, rehabilitation, and psychotherapy. Of late some psychiatrists have abandoned important aspects of their diagnostic and therapeutic work to psychologists, social workers and community nurses. These developments have gained their own momentum and only the future will decide whether they will be for good or ill. I still remain faithful to the ideal of the psychiatrist whose work is informed by Freud's psychoanalysis and whose clinical responsibilities span the whole range of mental disorders. 